\title{
Del cuerpo poético al cuerpo político. Figuras de la memoria en los cuerpos del teatro contemporáneo bogotano*
}

\author{
From the poetic body, to the political body. \\ Figures of memory in the bodies of contemporary Bogotá theater
}

Do corpo poético ao corpo político.

Figuras de memória nos corpos do teatro contemporâneo de Bogotá

Laura Jimena Silva Lurduy**

Universidad Autónoma Metropolitana, México, Universidad Santo Tomás, Bogotá.

Correo electrónico: jimenasilva822@gmail.com

Revista Corpo-grafías: Estudios críticos de y desde los cuerpos / Volumen 5 - Número 5 / Enero - diciembre de 2018 / ISSN impreso 2390-0288, ISSN digital 2590-9398 / Bogotá, D.C., Colombia / pp. 70-87.

Fecha de recepción: 20 de mayo de 2017

Fecha de aceptación: 12 de julio de 2017

Doi: https://doi.org/10.14483/25909398.14207

Cómo citar este artículo: Silva, L.J. (2018, enero-diciembre). Del cuerpo poético al cuerpo político. Figuras de la memoria en los cuerpos del teatro contemporáneo Bogotano. Revista Corpo-grafías: Estudios críticos de y desde los cuerpos, 5(5), p-p 70-87/ ISSN 2390-0288.

*Artículo de investigación artística

**Socióloga de la Universidad Autónoma Metropolitana de México en convenio con la Universidad Santo Tomás de Bogotá, y actriz en formación. Interesada por los temas políticos en coyuntura con las artes escénicas. Desde allí, abordó una investigación que tomó como punto de partida los estudios del cuerpo desde la mirada del teatro bogotano en sus últimos años, en la cual, se vislumbran múltiples formas de cuerpos poéticos en la escena, en el trabajo del actor y su relación con lo político y la memoria.

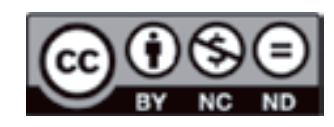




\section{Resumen}

En una conversación entre teatralidad, cuerpo y política el punto de partida y el punto de regreso puede ser hablar de memoria. En el desarrollo de este escrito se presenta una investigación que se nutre tanto de las ciencias sociales como de las artes, cuyo sujeto de estudio tiene relación con el trabajo de la teatralidad contemporánea en torno a la acción política de los cuerpos productores en la escena. Esta investigación se fundamenta en la tríada de estudio «arte, cuerpo, política» y desde allí, han suscitado indagaciones sobre el papel del arte y particularmente del teatro en el contexto colombiano actual modificado y transformado por procesos de violencia y conflicto en el país.

Los estudios del cuerpo como motivo de creación y acción artística, social y política generan un campo emergente para el análisis de distintos problemas contemporáneos que componen múltiples expresiones, manifestaciones e intervenciones; y hacen de ello una reflexión corporal teórico-práctica cotidiana. Asimismo, en el campo de las artes escénicas, estudiar el cuerpo podría ser de mil maneras resignificar el papel de la corporalidad, de concebir la acción artística y su función social y política. En el caso de Colombia, es a mediados del siglo pasado que grupos de teatro y colectivos artísticos, buscaron en algunos el reconocimiento del cuerpo, y en otros, la transformación de escenarios en conflicto que se presentaron en coyuntura de violencia política desde las corporalidades.

Cuerpo: medio, instrumento y obra de diversos usos artísticos; manifestación y representación de dinámicas y múltiples realidades sociales y políticas. A partir de lo anterior, la investigación tiene relación con el trabajo de -la teatralidaddesde una perspectiva contemporánea e interdisciplinar, cuya mirada hacia el cuerpo se remite como obra, espacio y herramienta vital de creación.

En este orden de ideas, el enfoque es presentar algunas luces de lo que fue la investigación de grado de manera teóricopráctica, exponer los acercamientos teóricos, metodológicos y reflexivos para dar a conocer el proceso llevado a cabo en los últimos tres años y reconocer la importancia sobre el lugar que ocupa el cuerpo en la teatralidad contemporánea colombiana, como práctica relevante para construir las narrativas en torno a lo político en el país y en nuestro contexto latinoamericano.

Palabras clave: cuerpo; teatralidad; política; Colombia.

\section{Abstract}

The following presentation arises from diverse theoretical and practical reflections that follow a continuous path between sociology and scenic arts. It is the result of a degree thesis, developed in the last two years before obtaining a Sociology degree in Bogotá, Colombia. Its object of study has a strong connection with the work of contemporary theater involving the political action human bodies hold, that comes from 3 long experiences theater groups that possess a direct relation to memory. Studying the body as a matter of creation and artistic, social and political action provides an arising field of study to analyze contemporary problems that take part in multiple expressions, manifestations and interventions; that is why it becomes a theoretical and practical reflection sociologically. The human body is understood as the first territory to be inhabited and ever inhabited, as a channel of sensations, thoughts, stories, concepts and non-concepts; it is the starting point of social experiences, interdependent from spaces and times, in which art comes together to be a master piece, and fuses with life. This research is therefore based on this triad of study: art, body and politics, and from that point on, some inquiries about the role of the art and specifically, of theater in the colombian context which has been permeated by a violence situation historically. With all of the above, the focus of this research is to clarify what the degree thesis was about theoretically and practically. That way, the theoretical, methodological and reflexive approaches are exposed in order to explain the process held in the last three years from the sociological field. Theater is definitely considered a very importante practic that builds new narratives around the political matters of a country, and in Latinoamerica.

Keywords: body; theatrically; politics; Colombia. 


\section{Resumo}

Numa conversa entre teatralidade, corpo e política, o ponto de partida e o ponto de retorno podem ser falar da memória. No desenvolvimento deste trabalho uma investigação que alimenta ambas as ciências sociais e as artes que é apresentado, que sujeto estudo está relacionada ao trabalho de teatralidade contemporânea sobre a ação política dos organismos produtores na cena. Esta pesquisa é baseada na tríade de arte' estudo, a política do corpo “e, de lá, levantaram perguntas sobre o papel da arte e particularmente teatro no contexto colombiano atual modificada e transformada por processos de violência e conflito no país.

Os estudos do corpo como motivo de criação e ação artísticas, sociais e políticas geram um campo emergente para a análise de diferentes problemas contemporâneos que compõem múltiplas expressões, manifestações e intervenções; e torná-lo uma reflexão corporal teórico-prática diária. Da mesma forma, no campo das artes cênicas, estudar o corpo poderia ser mil maneiras de ressignificar o papel da corporalidade, conceber a ação artística e sua função social e política. No caso da Colômbia, é a meados do século passado, grupos de teatro e coletivos de arte, procurou algum reconhecimento do corpo, e em outros, a transformação de cenários de conflito que surgiu em circunstâncias de violência política de corporalidade.

Corpo, meio, instrumento e trabalho de vários usos artísticos; manifestação e representação de dinâmicas e múltiplas realidades sociais e políticas. Do acima exposto, a investigação está relacionada com a teatralidade -a trabalho a partir de uma perspectiva contemporânea e interdisciplinar, cujo olhar para o corpo é referido como um espaço de trabalho e ferramenta de criação vital.

Nesse sentido, o foco é apresentar alguns destaques do que estava investigando grau de teóricos e práticos, expor as abordagens teóricas, metodológicas e pensativo para divulgar o processo realizado nos últimos três anos e reconhecem a importância do lugar que o corpo ocupa na teatralidade colombiana contemporânea, como uma prática relevante para construir narrativas em torno do político no país e em nosso contexto latino-americano.

Palavras-chave: corpo; teatralidade; política; Colombia. 


\section{Introducción}

¿Cómo desarrollar una investigación en teatro desde las ciencias sociales? ¿Por qué es importante el estudio de los cuerpos desde unas miradas artísticas? ¿Cómo ubicar elementos poéticos como elementos políticos? ¿Cómo el cuerpo puede tener una experiencia política? ¿Podríamos hablar de un teatro político desde los cuerpos en Bogotá y en Colombia? Las anteriores, son algunas de las preguntas que inspiraron y son el resultado de un trabajo de investigación entre la relación teatro-corporalidades-lo político.

El cuerpo es la relación primaria con el mundo: es un conjunto de órganos, carne viva, tejidos, células y otros componentes biológicos, y, también es construido por un sentido social y colectivo: las interacciones, experiencias y dinámicas sociales se construyen desde él mismo. Es ese primer territorio que habita y es habitado en tiempo, espacio, espíritu y carne, escenario de sensación, pensamiento, construcción, desconstrucción: el punto cero de la experiencia social. Es el lugar donde percibimos, actuamos, transformamos y encarnamos diferentes realidades sociales y nos comunicamos con el mundo. Por lo cual, abordar la corporalidad como problema y reflexión es indagar nuestra propia condición humana. En la teatralidad contemporánea, el cuerpo es recurso, obra de arte: la búsqueda y el encuentro, o mejor: el proceso y la síntesis.

Para un diálogo entre cuerpo-teatralidad-política, en primer lugar, se identifican las prácticas del cuerpo desde la escena, posteriormente, se describe la acción política en los procesos de creación y finalmente se buscan las figuras de la memoria en las prácticas del cuerpo inspiradas en el libro Figuras de lo Pensable de Castoriadis. Para ello, las prácticas, la imagen, la representación, el papel del texto y el contexto son relevantes desde el lugar de la experiencia corporal en los colectivos artísticos de larga trayectoria en Bogotá que han aportado de manera significativa al movimiento y la creación a nivel local y nacional.

Profundizando desde sus diversas dramaturgias el sinnúmero de posibilidades que tiene el cuerpo en sus formas poéticas, metáforas, relatos, relaciones políticas en la escena, se aborda la dimensión política de la práctica teatral contemporánea, desde sus acciones políticas y contenidos políticos; el estrecho vínculo con los públicos, el sentido común y colectivo, la permanencia en un teatro comprometido con los acontecimientos de coyuntura en la ciudad y el país; así como el registro de Bertold Brecht y Antonin Artaud en sus creaciones.

En cada colectivo una pieza teatral, en donde el cuerpo es el lugar de enunciación e implicación política desde diferentes dimensiones: «cuerpo ausento, cuerpo expuesto, cuerpo habitado». En tercer momento se busca comprender cómo el cuerpo tiene una experiencia política, la manera como se realiza una caracterización desde el cuerpo y la acción política a través de las categorías de análisis y los resultados, descubriendo las similitudes y diferencias de los grupos y sus obras. Desde allí, la visión del cuerpo como implicación política es más clara, dado que es más visible el cuerpo como un territorio en el que recaen figuras sociales representativas, como el desarraigo, la resistencia, la denuncia, la trasgresión, la fragilidad, entre otros, que desembocan como figuras de la memoria.

\section{Metodología}

La metodología se realizó sobre una base cualitativa, con el fin de reunir la teoría y la práctica desde las voces de los productores/ intérpretes de la teatralidad. Debido a que el tema de trabajo esencial tuvo su centro en las múltiples percepciones, construcciones y prácticas continuas de la teatralidad contemporánea y sus corporalidades, esto implicó creaciones, sensibilidades y afecciones que difícilmente son posibles de analizar por otra metodología. Desde una perspectiva de la fenomenología, cuya fuente clave para los 
estudios cualitativos es reivindican la posición de las subjetividades y la comprensión hacia las particularidades de los fenómenos sociales, la investigación viró con este objetivo. Por lo anterior, la investigación contuvo los aportes de la fenomenología propuesta por el autor Maurice Merleau-Ponty (1957), pues el cuerpo resulta un hecho fundamental de estudio y análisis.

La investigación se realizó con tres grupos de teatro en Bogotá, que sitúan sus propuestas y las desarrollan en la ciudad y en otras regiones del país. Además, cuentan con una trayectoria mayor a 20 años en el campo de las artes escénicas y se han posicionado como grupos relevantes e influyentes en propuestas y obras de teatro. En esta investigación son los productores de las piezas teatrales, los contenidos, y las prácticas corporales. Umbral Teatro: Grupo de teatro creado en 1991 con la dirección de Carolina Vivas (directora, dramaturga y actriz colombiana) e Ignacio Rodríguez (director, músico y actor), quienes desde la perspectiva del método de creación colectiva y los estudios con Santiago García y el Teatro la Candelaria fundaron el grupo. Teatro Vreve - Proyecto teatral: Colectivo teatral que se consolida en el 2002 bajo la dirección de Víctor Viviescas (director y dramaturgo) y Fernando Pautt (actor e investigador), quienes ha generado propuestas teóricas, de investigación y de montajes en torno a la construcción de dramaturgias contemporáneas de autor y propias. Fundación Vendimia Teatro: grupo de teatro que se origina bajo la dirección de Carlos Araque (antropólogo, director y actor; docente Facultad de Artes ASAB) y Gilma Mora en 1987, quienes consolidaron bajo la figura de fundación desarrollar propuestas escénicas cercanas a un tipo de teatro popular y antropológico.

En cuanto a las estrategias y técnicas de recolección de la información de acuerdo con la investigación cualitativa, se desarrollaron técnicas de recolección de la información: entrevistas semiestructuradas, observación no participante y análisis de contenido categorial. Se realizaron entrevistas por grupo y productores (directora, director, actriz o actor), con un total de siete entrevistas semiestructuradas, diseñados por investigación previa al grupo y sistematizadas por categorías de análisis. Se construyeron diarios de campo para la observación no participante de las obras teatrales. Y para el análisis de contenido categorial: contenidos de piezas teatrales se revisaron los procesos creativos de acuerdo con matrices que desarrollan en detalle la composición artística por contenido categorial. La investigación de las piezas teatrales se compone del texto dramático, de los subtextos, las acotaciones, las acciones, los elementos visuales y auditivos que dan pie a una estructura general. Para este análisis, hemos considerado la comprensión del personaje, el sentido de la dramaturgia a través de sus autores, la expresión corporal, la interpretación y el nudo analítico de cada obra. Para arrojar los contenidos de la investigación en relación con la memoria, se tiene pensado ampliar la investigación a la aplicación de herramientas metodológicas que ponen el cuerpo como centro con grupos de teatro en la ciudad que reivindique su lugar en la escena y las escrituras.

\section{Resultados \\ Cuerpo: recurso artístico y obra de arte}

El cuerpo es la base del hacer artístico y teatral: puede ser signo, símbolo, significado o superficie en las obras y en las dramaturgias, por lo tanto, cobra usos y prácticas diversas y renovadas permanentemente. Se construye como traductor de la experiencia individual y colectiva, pues en palabras del maestro Santiago García (1999): "el teatro exige la presencia del cuerpo del actor como ejecutando de las acciones que componen una obra o dramaturgia presentado y pensado para otros" (pp. 12). Sin el cuerpo del actor, un público y un escenario, no hay teatro, esta es la condición-Sine qua non- para la existencia de la teatralidad contemporánea, pues es el cuerpo humano, la encarnación de la presentación y representación de la obra, el motor de y principio para la actividad social y la creación artística. 
Cuando Jean-Luc Nancy (2010) planteaba en su obra Corpus que no se tiene un cuerpo, sino que se es un cuerpo, se encarna y se existe en el mismo, quiere decir que el cuerpo es el acontecimiento propio, tiene un efecto de materialidad, en este caso, es el cuerpo el que ocupa una relación fundamental con la creación, los contenidos y la metodología de trabajo. Específicamente en las dramaturgias contemporáneas bogotanas, en las cuales, la síntesis y manifestaciones de trabajo se resumen en el cuerpo del actor/actriz. Carolina Vivas, directora y dramaturgia de Umbral Teatro, sostiene: "El cuerpo son varios cuerpos a la vez: el cuerpo del actor/actriz; el cuerpo y el espacio; y el cuerpo y su contexto: Todo se concentra y pasa por un cuerpo" (Entrevista a Carolina Vivas, 2017).

Ahora bien, las dramaturgias son entendidas como las estructuras narrativas, literarias, que dan sentido al contenido y representación de la obra. Se presentan de formas diversas y se transforman desde el tiempo y el espacio de acuerdo al grupo teatral. En este caso, las tres dramaturgias convergen en hablar un sentido de tiempo presente y cuerpo presente, pues si bien, las temáticas y los contenidos no están preestablecidos en los grupos, los fenómenos actuales y los acontecimientos de coyuntura social y política son materializados a través del cuerpo y su sentido en el presente.

En este orden, las prácticas del cuerpo en la teatralidad, se transforman de acuerdo a tipos de creación dramatúrgica: de creación colectiva, de obra de autor, o de diálogos entre dirección-autor-representación siempre en un contexto actual: "hablar de un presente, no únicamente en el uso de nuevas tecnologías y herramientas visuales. Puede haber una obra contemporánea donde el cuerpo sea el único objeto en el espacio y también lo hace contemporáneo. Los lenguajes y la técnica son un medio para hacerlo posible" (Entrevista a Ignacio Rodríguez, 2017).

Umbral Teatro, desde la dramaturgia de lo sutil, propone formas o vías de acceso al cuerpo de forma poética, detallada y metafórica; hablar de los acontecimientos que aquejan el país, desde allí, un componente importante es la fuente testimonial, los relatos y las historias recuperadas con diálogos en los territorios de conflicto, las memorias de los actores, actrices y las propias de los directores:

Lo contemporáneo lo componen los detalles, lo mínimo, lo pequeño, lo poético son el antecedente de conflictos mayores que desembocan en la obra. En donde el papel de los actores, y los directores es condensar y sintetizar, y que logre llegar al público mediante múltiples lecturas (Entrevista a Rodríguez, 2017).

De manera que la dramaturgia en Umbral Teatro desarrolla una estructura dramática hasta llegar a la composición de las figuras corporales, son las que dan cuerpo al cuerpo, se trabajan de formas sutiles, casi imperceptibles, para hablar de problemas que implicarían elementos de conflicto o hablarían de la guerra, de modo, que los elementos artísticos son construidos para contar realidades tan fuertes de maneras poéticas y casi que invisibles.

Por otro lado, en el caso de Teatro Vreve, según Víctor Viviescas (2017): el cuerpo consiste en una superficie donde se expone la obra, es el recurso esencial del actor y la actriz, y en cuanto a su dramaturgia -Dramaturgia de los bordes- el cuerpo en las obras consiste en darle una presencia al espacio y una relación con los materiales o recursos escénicos. En palabras de su director: "Hay obras que concentran toda su importancia en el cuerpo, o hay obras en las que hay que poner a los actores prácticamente solos en el escenario, prácticamente toda la expresividad del actor puesta en el cuerpo" (Entrevista a Víctor Viviescas, 2017).

Por otra parte, desde la mirada del Teatro posdramático o poshistórico a lo que Carlos Araque, director de Vendimia Teatro, planteó como Dramaturgia en diferencia, se escribe lo siguiente: "El posmodernismo posibilita que el artista como tal se convierta en obra de arte" 
(Araque, 2017). Es una propuesta sustentada en la corriente de teatro posmoderno que indagó Hans Thiels Thilemann, en la cual no hay distinción entre cuerpo-obra, cuerpo-mente, cuerpo-vida y que busca efectos de representación corporal en sus públicos. Por lo cual, su director señala:

La dramaturgia actual está influenciada por la reflexividad, no significa solo reflexionar sobre sí mismo, sino propugnar por una conciencia inmediata de lo que se escribe para la escena, se hace en la escena, el teatro es cínico, irónico e incluso irreverente. El teatro poshistórico está atravesado por tres grandes dilemas: representación-presentación, reproducción-producción; legitimación-legalización (Araque, 2013, p. 35).

En este orden, las dramaturgias se ponen en diálogo con múltiples lenguajes teatrales para dar cuenta de sus contenidos, en donde el cuerpo es la razón fundamental de la escena y la creación, objeto y sujeto de investigación y del acontecimiento.

Dramaturgia de lo sutil, Dramaturgia de los bordes, y Dramaturgia en diferencia posicionan la corporalidad como recurso vital propio desde sus diversas dramaturgias, en las cuales se reúnen disciplinas artísticas como la danza, el cine, las artes plásticas y las herramientas audiovisuales. Sin embargo, esto se transforma de acuerdo con el grupo de trabajo en sus técnicas y adecuaciones en las piezas teatrales. Por lo cual, los lenguajes teatrales son reinventados permanentemente de acuerdo con los contenidos y los recursos artísticos de cada grupo, siempre teniendo en cuenta la relación entre significado, acción y contenido.

Ahora bien, cada creación o montaje tiene una relación distinta con el cuerpo: El cuerpo-el tiempo-el espacio, son relaciones que dan sentido al mensaje de pieza escénica. Particularmente, las prácticas corporales se desarrollan en dos momentos: unos momentos individuales y unos momentos colectivos "es el reconocimiento del mi cuerpo en el espacio, de mi cuerpo consigo mismo, de mi cuerpo frente a otros cuerpos, frente al otro, y frente a lo otro" (Entrevista a Carolina Vivas, 2017). Por lo cual, la dinámica individual y colectiva complementan las teatralidades sobre un trabajo del cuerpo, la voz, el texto y el contexto social de las temáticas.

\section{La geografía de los nervios. Acto III: La carne, el cuerpo}

-Artaud: Mi culto no es el yo sino el cuerpo, en el sentido sensible de la palabra cuerpo. Las cosas me atañen en la medida que afectan mi cuerpo, que coinciden con él, que lo conmueven y no más allá. Me atañe y me interesa nada más lo que se dirige directamente a mi carne. Y ustedes hablándome del yo social, del ser en la cultura... Soy hombre de mis manos, mis pies, mi vientre, mi corazón, mi carne comestible y mis vísceras. Me hablan de palabras, de significados, de ideas; pero no se trata de pensamientos sino de la duración de la carne, al lado de la carne está la vida, está el ser humano en cuyo circulo gira eso que llamamos hambre...Que le falte la lengua a mi cuerpo, las ideas a mi mente, pero que no me priven de la posibilidad de entretejer mi cuerpo con otros cuerpos (Araque, 2013, p. 104).

En Umbral Teatro la preparación corporal es necesaria y entendida como un conjunto entre lo físico, lo musical, lo emocional y lo espiritual, en donde deben construirse unas partituras exactas del cuerpo para narrar y contar las historias. La voz y la música ocupan un papel fundamental. David Le Breton (2010) afirmó: "El cuerpo es el receptáculo del personaje, hay que considerar también el trabajo de la voz, la dicción, la articulación, el ritmo de la elocución, pero la voz es también parte sensible del cuerpo, entre la carne y la palabra” (Le Breton, 2010). 
En contraste, en Vendimia Teatro, la esencia de la teatralidad consiste en hacer un equilibrio entre el texto y el cuerpo, son las dos herramientas fundamentales mientras que en Teatro Vreve, no existen unas prácticas definidas para trabajar el cuerpo. De tal manera, podemos encontrar que las corrientes del teatro contemporáneo se componen de corrientes como "el teatro físico" , "el teatro pobre" y "el teatro posdramático" , sin embargo, hablando de técnicas corporales-artísticas siempre está presente el trabajo de Vsévolod Meyerhold, quien plantea que el oficio del actor consiste en situar su cuerpo, todo su cuerpo tiene que estar presente en el espacio, pues mediante el conjunto de movimientos y gestos representa su condición social, "el actor tenía que ser un artista proletario con conciencia de clase y deberes productivos que hiciera de su trabajo una práctica política” (Dubatti, 2003).

Particularmente, en Vendimia Teatro, las prácticas están orientadas desde el entrenamiento de Theodorus Terzoupulos, Eugenio Barba, Grotowsky y las formas propias de entrenamiento del grupo. Como ya se ha visto, el cuerpo tiene una posición esencial, y está en permanente relación con otros elementos que lo componen como la voz, el contexto y el texto dramático, lo cual podría comprenderse como un sentido práctico de la acción corporal. Por ejemplo, para el actor José Luis Díaz, protagonista de "Donde se descomponen las colas de los burros" el cuerpo fue el recurso vital de la imagen teatral y la representación de los contenidos de la obra:

Imagen1. José Luis Díaz, Escena: La rebelión en Donde se descomponen las colas de los burros Foto: Gabriela Córdoba Vivas. Dramaturgia y presente 
Por lo anterior, cada montaje se plantea unas necesidades y unas preguntas que se hace el cuerpo del actor/ actriz frente a su experiencia vivida para generar imágenes y representaciones desde el cuerpo, en donde el papel de la subjetividad, la memoria y los recuerdos ocupan un lugar esencial.

La actriz debía construir una imagen teatral desde sus memorias" (Vivas, p. 101). En el sentido que señala Patricia Pavis, donde "la imagen juega un gran rol en la práctica teatral contemporánea, pues ella se volvió la expresión y la noción que se opone a estas del texto, de la fábula o de la acción" (Entrevista a Carolina Vivas, 2017). Por lo anterior, en la teatralidad contemporánea el trabajo tiene una estrecha relación con la memoria como sinónimo de experiencia, en donde la memoria corporal y el silencio están íntimamente relacionados. Pues es el encuentro de los recursos del actor/actriz como individuo y los recursos creativos del grupo. Por ello, hablar de una memoria corporal, significa hablar de un pasado y un presente en la subjetividad y en la construcción de la dramaturgia.

\section{Metáforas: violencia y fragilidad}

Los procesos de creación tienen una profunda relación con el conflicto y la violencia en Colombia. El cuerpo ocupa un papel preciso en los temas de la guerra, ya que en él se representan los vestigios del dolor y las violencias corporales: cuerpos-ausentes, cuerpos-expuestos, cuerpos-relatos son algunas de las metáforas que proyectan las imágenes del cuerpo en las dramaturgias y las piezas teatrales.

Relacionando con el tema de la violencia, en Teatro Vreve, el concepto de fragilidad es asunto de investigación y creación, un cuerpo frágil permeado por relaciones de poder y violencias simbólicas es permanente. El concepto de fragilidad es la columna vertebral de las obras, para su director, se habla "En términos de la fragilidad de lo humano, la injusticia y tema de la barbarie en la vida cotidiana" (Entrevista a Víctor Viviescas, 2017).

Por otro lado, el trabajo teatral en algunos territorios, zonas de conflicto en diversas regiones del país es una parte importante para Umbral Teatro, hay un trabajo en campo permanente, de recolección de narrativas, acompañado de procesos pedagógicos y un trabajo de memoria desde los cuerpos. Pues en el grupo, por dentro y por fuera de las obras, el cuerpo es el espacio de síntesis de las violencias de orden político, social y simbólico, los conflictos armados, los temas de la guerra: "La violencia se deja ver como fenómeno corporal física y espiritualmente, por cual el trabajo riguroso del cuerpo deja ver estas evidencias" (Entrevista a Carolina Vivas, 2017).

En este sentido, la relación con lo político es imprescindible, puede ser comprendido desde diferentes vértices: primero, la formación del sujeto político; segundo, los grados de agenciamiento o transformación; tercero, la cercanía a la denuncia, la militancia, el activismo, la resistencia o los asuntos de la guerra; y cuarto, la similitud con la acción colectiva, el sentido comúncolectivo y el conflicto. Elementos que reúnen la dimensión integral de la acción política y son expresados a través del cuerpo.

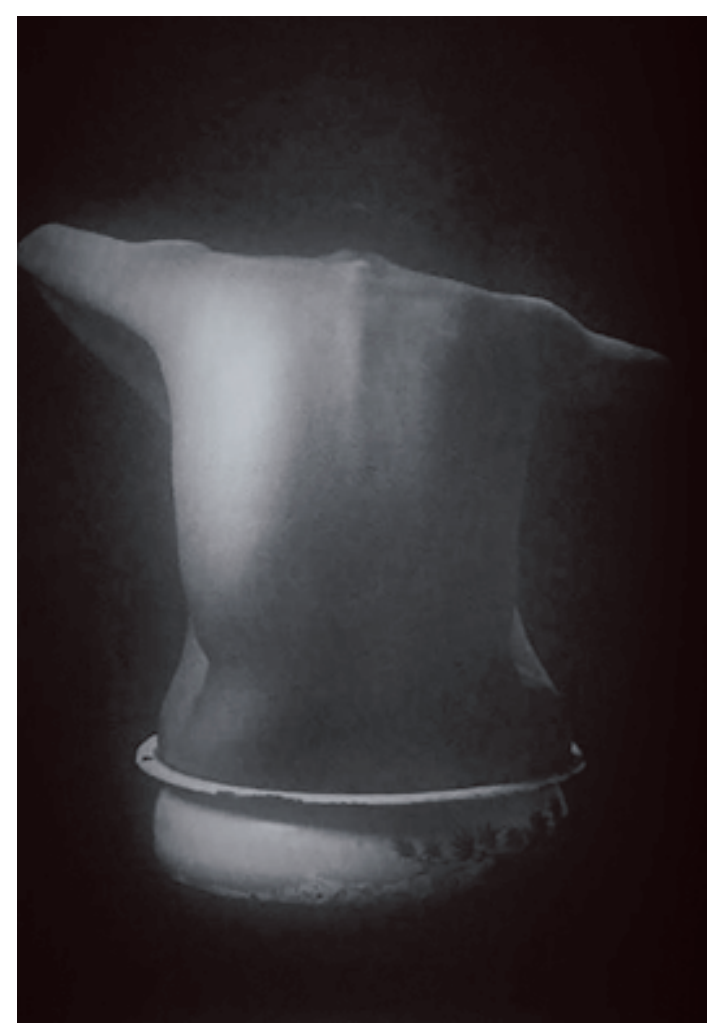

Imagen 2. Carolina Beltrán en Filialidades Foto: Umbral Teatro. Dramaturgia de los sutil, 2012 


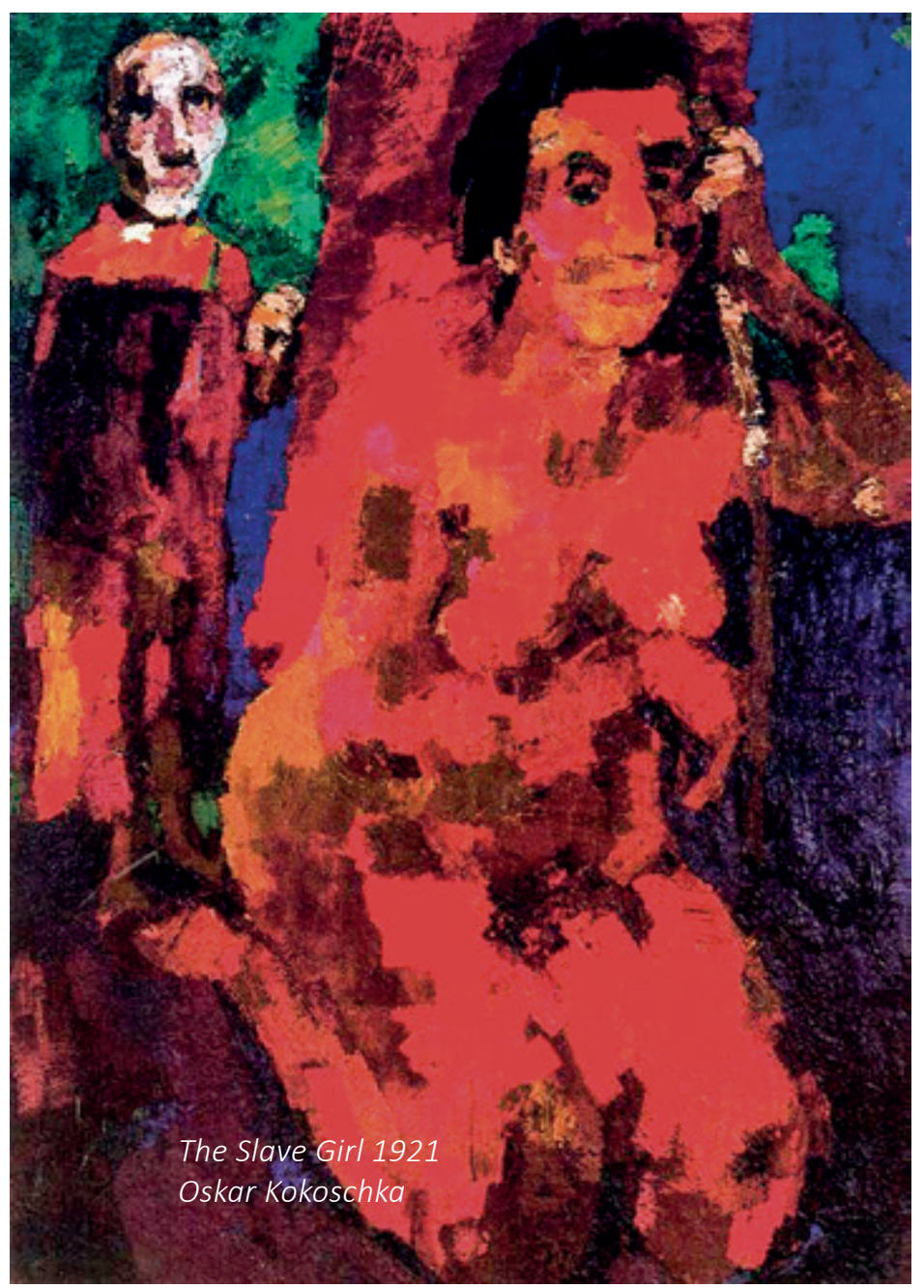

En este orden, la acción política es entendida como una práctica y una experiencia. Es una práctica que se realiza de manera individual y también colectiva, que se vive de manera subjetiva y en un sentido común. Rancière plantea que "la política es en primer lugar el conflicto acerca de la existencia de un escenario común, la existencia y la calidad de quienes están presentes en él" (Rancière, 2007, p. 41). De tal manera, propone que lo político es una práctica que se manifiesta en transformación a los espacios sociales entre el espacio y la experiencia humana:

Es una delimitación de tiempos y espacios, de lo visible y lo invisible, de la palabra y el ruido, de lo que define a la vez el lugar y el dilema de la política como forma de experiencia. La política se refiere a lo que se ve y a lo que se puede decir, a quién tiene competencia para ver y calidad para decir, a las propiedades de los espacios y del tiempo desde las prácticas artísticas (Rancière, 2009, p. 3).

A lo que se refiere con acción política, como hemos visto en Rancière es una forma de práctica, pues los actos estéticos son configuraciones de la experiencia que posibilitan modos nuevos del sentir y por ello mismo, nuevas formas de acción política:

Me interesa el que se pueda conectar con la vivencia, con lo que se llama "el convivio", lo experiencia, la poiesis, que es el acto vivo que nos involucra poéticamente a los dos, o el convivio que es una palabra primero sinónimo de banquete, y ahora manifiesta comulgar el emocional en lo sensitivo (Entrevista a Carlos Araque, 2017).

En este sentido, la acción política va ineludiblemente relacionada con las prácticas artísticas y las formas de estéticas relacionales: "La política necesita conocer el ámbito artístico, sus sujetos, prácticas y objetos, y a la vez el arte posibilidad modos cognitivos particulares, específicos y diversos de los habituales respecto de los fenómenos sociopolíticos" (Rancière, 2010, p. 10). Como se ha dicho, Rancière (2010) sostiene que lo político es más visible en las prácticas artísticas, pues son ellas las que reúnen el disenso, la relación entre actores y públicos, la distribución de lo sensible y la experiencia estética: "son maneras de hacer que intervienen en la distribución general de las maneras de hacer y en sus relaciones con (las) maneras de ser y (las) maneras de (su) visibilidad (Rancière, 2009, pp. 10-11).

En este orden de ideas, no nos referimos a que hay un teatro político definido o algunas formas específicas de hacer teatro político, nos referimos al ejercicio de acción política que es enunciada, manifestada y expresada a través del cuerpo y la participación. Por ello, la acción política hace una ruptura en la configuración de lo sensible, el orden de los cuerpos y el espacio de acción. Por ejemplo, en Teatro Vreve, su director sostiene: 
Esto es político todo. Es la línea que atraviesa nuestro trabajado. En termino formales las trasformaciones de la dramaturgia como las nuevas escrituras, pero en términos temáticos el concepto de fragilidad del sujeto, que se puede ver sonar un poco abstracto, es precisamente porque creemos que la condición del sujeto puede verse en diversos contextos poéticos, políticos y sociales. En mi propia escritura vemos las condiciones historiadas de ese concepto de fragilidad del sujeto, y esa historización pasa por un proceso de tomar posición política, el teatro de Teatro Vreve es profundamente político (Entrevista a Víctor Viviescas, 2017).

\section{Un teatro comprometido. Públicos y acontecimientos}

Cuando hablamos de política vemos como en Rancière hay dos elementos principales sobre la presencia y la práctica, y sobre las cuales se pueden consolidar las obras teatrales. Ahora bien, si bien la acción política puede ser leída desde los artistas y los creadores, es decir, sus productores, también tiene una estrecha relación con los públicos, los espectadores y quienes siempre hacen parte de la obra teatral, pues para los productores, la obra siempre está compuesta de dos elementos principales: el actor y sus públicos.

Para Liliana Cortes Garzón (2008) "Brecht y Artaud proclamaron la necesidad de un teatro sin espectadores, un teatro que se piense como drama, como acción, como una actividad realizada por cuerpos vivos frente a cuerpos vivos, que se base en el poder del acto", pues a manera de reivindicación de la potencia reflexiva de los acontecimientos político y sociales evidenciados en la obra, es sumamente importante la labor de los públicos. De manera que podemos ver como Brecht y Artaud influenciaron en la posición de los grupos por incluir a los públicos en sus obras, como parte o participes de las mismas.

En el caso de Umbral Teatro hay una necesidad de llegar a los públicos, se reflexiona permanentemente por la tarea del artista en el público, un conflicto latente sentido y afectado por todos, generar una afección en los espectadores es muy importante:

Uno trabaja fundamentalmente para tocar el alma del espectador. Si eso no sucede, no estamos haciendo nada.

Porque esto es una acción, un acto entre alguien que lee y ve. Pero si yo no conmuevo y no toco. Yo creo que la tarea

del artista siempre es conmover, tocar, hacer reflexionar (Entrevista a Ignacio Rodríguez, 2017).

No es un grupo que hace teatro político, pero si es un grupo que le inquieta hablar de lo que le pasa a esta sociedad. Hablar y denunciar cosas que no se han tocado. En la obra "La que no fue", por ejemplo, habla de la mujer, de su papel en la sociedad. No está hablando de un teatro político, pero si habla de cosas que nos interesa decirle a la sociedad (Entrevista a Carolina Vivas, 2017).

Ahora bien, la afección que las obras generan en los públicos es permanente, si bien por parte de sus productores no hay un posicionamiento con el teatro político, o teatro militante, hay una posición de denuncia frente a las realidades del país en conexión con los recursos artísticos que llega a sus espectadores, es un mensaje que efectivamente logra codificarse.

Con las obras nunca pensamos que la obra iba a generar lo que genera. Es decir, Carolina nunca es sorda o muda ante las cosas que hay que decir en el país. Para denunciar. Para poner al Estado presente. Tenemos que ver por qué paso, quien genera eso, sin el ánimo de ser "panfletudos", ni militantes, si se trata de hacer una propuesta política clara (Entrevista a Andrea Sánchez, 2017). 


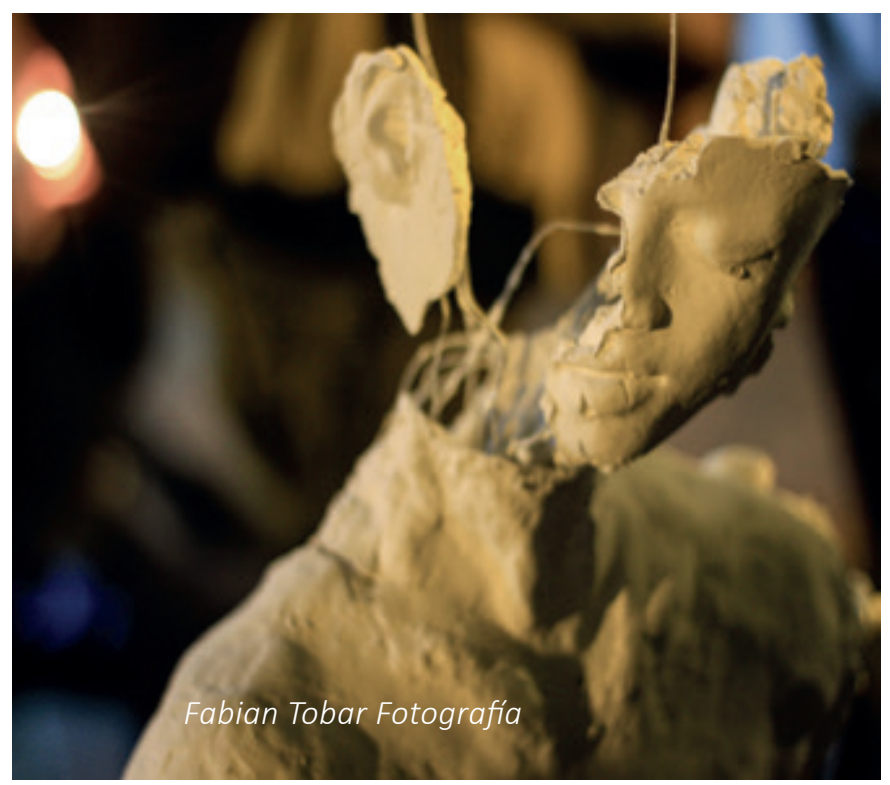

Por lo anterior, conmover y llegar a los públicos se logra desde la puesta en escena y el despliegue de la representación del cuerpo en las obras. Sin embargo, también el contacto y la presencia del público es importante, se generan espacios de discusión para hablar con los espectadores, que de manera diversa manifiestan su emoción, posición y entendimiento de la pieza teatral. Así mismo, son el aliciente fundamental de la composición de los productores de las mismas.

\section{El legado de Brecht y Artaud}

Ahora bien, los componentes históricos y transversales del teatro político en las maneras de hacer de los teatristas en Bogotá y Colombia, suponen un legado de Bertold Brecht (1983) y Antonin Artaud (1996) como pilar de la creación teatral. La apuesta de Brecht, se basa en el precepto de que el teatro no reproduce o inventa situaciones, sino que las descubre a partir de sus interrupciones, las que generan un distanciamiento frente a la obra y sus contenidos. Las situaciones son siempre escenarios que ocurren habitualmente en el desarrollo socio-político, las que, sin embargo, se muestran en la propuesta de Brecht con asombro o con distancia, una distancia que pretende generar en el espectador conciencia ante lo que se le presente y una posición política al respecto, en el caso de Umbral Teatro y Vendimia Teatro.

Brecht decía: quiero que de mis obras salga la gente reflexionando sobre sí mismo, y reflexionando sobre su propia vida. Ese proceso de la gente reconocerse, es maravilloso, pero eso tiene algo tras, nosotros hemos logrado se ha logrado ir decantando unos procedimientos de trabajo con la comunidad que se van cualificando (Entrevista a Carolina Vivas, 2017).

Asimismo, en los actores, el distanciamiento propuesto por Brecht tiene una función social y política, pues actores y actrices siempre están tomando una postura o posición frente al papel o personaje en representación. Bertold Brecht pensaba que, en el sentido teatral, la función del espectador debe convertirse en el cuerpo vivo de la obra, un receptor activo y que indague en sí mismo y en la obra misma. Lo que para Rancière se basa en una serie de equivalencias y oposiciones que deben ser discutidas, por lo que las herramientas pedagógicas y reflexivas serán fundamentales, de allí que los grupos de la teatralidad contemporánea contemplen en sus maneras de hacer teatro las influencias del teatro del mismo Brecht, de Artaud y de Augusto Boal, en donde los espectadores y las comunidades son los mismos creadores y creadoras.

Nuestro público es un circuito reducido de influencia, más que a donde logramos llegar, es a quienes logramos que llegue". (Entrevista a Víctor Viviescas, 2017). En Teatro Vreve, la acción política tiene una relación con los poderes que recaen en el cuerpo, lo cual se deja ver en cada una de sus obras. El cuerpo es el lugar donde se escriben las relaciones de poder constantemente. 


\section{El lugar de la memoria}

Así las cosas, el campo de la experiencia política implica la transformación de ámbitos de la vida, en los que lo político se experimenta en el cuerpo. El cuerpo es el lugar político. Si hablamos de territorio, que es donde se generan los conflictos políticos. El único territorio que nos pertenece y que podemos manejar, es nuestro cuerpo. Desde destruirlo hasta volverlo un altar, y lo puedes hacer socialmente.

En el siguiente cuadro podemos evidenciar como la apuesta de las piezas teatrales y los recursos corporales, permiten encontrar figuras socio-políticas, -inspiradas en figuras de lo pensable de Cornelius Castoriadis-, desde la representación como denuncia, resistencias, composiciones de la identidad, experimentadas a través del cuerpo. Las memorias, la desaparición, el desarraigo, la identidad, y la fragilidad son encarnadas mediante productos sociales. Por lo cual, podríamos decir que las miradas de la acción política son múltiples, pero en esta exploración los sucesos y significados sociales tienen un vehículo que transmite el contenido artístico: el cuerpo.

\begin{tabular}{|c|c|c|c|}
\hline $\begin{array}{c}\text { Prácticas del } \\
\text { cuerpo }\end{array}$ & Acción política & Figuras & Obra \\
\hline $\begin{array}{c}\text { Signo } \\
\text { Acción } \\
\text { Interacciones } \\
\text { simbólicas }\end{array}$ & Sujeto político & $\begin{array}{l}\text { Desaparición } \\
\text { Segregación } \\
\text { Desarraigo }\end{array}$ & $\begin{array}{c}\text { Donde se descomponen las colas de los burros } \\
\text { De peinetas que hablan y otras rarezas }\end{array}$ \\
\hline $\begin{array}{l}\text { Memoria } \\
\text { corporal }\end{array}$ & $\begin{array}{c}\text { Experiencia } \\
\text { Agenciamiento- } \\
\text { transformación }\end{array}$ & $\begin{array}{c}\text { Desaparición } \\
\text { Violencia política }\end{array}$ & Donde se descomponen las colas de los burros \\
\hline $\begin{array}{l}\text { Violencia } \\
\text { corporal }\end{array}$ & $\begin{array}{c}\text { Denuncia } \\
\text { Experiencia } \\
\text { Denuncia } \\
\text { Existencia }\end{array}$ & Resistencia & $\begin{array}{l}\text { La técnica del hombre blanco } \\
\text { De pelonas Tilicas y Calacas }\end{array}$ \\
\hline $\begin{array}{l}\text { Memoria } \\
\text { corporal }\end{array}$ & $\begin{array}{l}\text { Denuncia } \\
\text { Conflicto }\end{array}$ & Memoria & Los adioses de José \\
\hline Subjetividad & Sujeto político & Identidad & La geografía de los nervios \\
\hline $\begin{array}{l}\text { Interacciones } \\
\text { simbólicas }\end{array}$ & Denuncia & Fragilidad & La técnica del hombre blanco \\
\hline
\end{tabular}

Desde la mirada de sus productores (actores, actrices, directores, dramaturgos y dramaturgas) la representación corporal tiene una implicación política en fenómenos y problemáticas sociales vigentes. Dicho esto, el lugar que ocupa el cuerpo en los espacios y las relaciones socio temporales está vinculado con los lugares de la memoria. Ya que desde los productores, hablar de la realidad social colombiana implica reconocer la memoria como punto de llegada, pues desde los relatos, las versiones pasadas y presentes, las reflexiones de los acontecimientos de violencia política, corporal y urbana se vislumbran en la corporalidad, lo cual nos lleva a diseñar una caracterización de figuras sociales y políticas que aparecen en los análisis expuestos. 
El arte desde aquí no busca ver los fenómenos sociales de lejos, al contrario, busca profundizar en la particularidad, en los seres humanos, con nombre propio, historia. En relación a esto, la autora Anne Huffschmid (2013) sostiene "Esta narrativa nos lleva a pensar en la "copresencia de los actores" (Schlögel, 2009: 10) que no sería otra cosa que la "copresencia" de los cuerpos, en el sentido de Goffmann, de interacciones focalizadas (el roce, el intercambio de miradas, la producción conjunta" (Huffschmid, 2013)

Por otro aparte, en los hallazgos del análisis de las piezas teatrales vemos como los resultados arrojan las figuras del cuerpo-ausente; cuerpo-expuesto; el cuerpo-habitado tanto en las líneas narrativas como las figuras del cuerpo del productor o productora.

\begin{tabular}{|c|c|c|}
\hline Cuerpo-ausente & $\begin{array}{l}\text { El cuerpo de Salvador representa la figura } \\
\text { de cuerpo ausente en la obra, a través de las } \\
\text { alegorías y las líneas narrativas se dejan ver los } \\
\text { lazos sociales que se quiebran un episodio de } \\
\text { tragedia. } \\
\text { De igual manera, el cuerpo ausente del } \\
\text { protagonista, en quien recaen los poderes y } \\
\text { el fenómeno de la desaparición forzada es el } \\
\text { cuerpo que desemboca el conflicto dramático. } \\
\text { En palabras de Huffschmid "La representación } \\
\text { memorial delo ausente encarnado en un cuerpo". }\end{array}$ & $\begin{array}{l}\text { Salvador: "Mientras nadie me encarne, me } \\
\text { recuerde o me imagine, simplemente estaré a } \\
\text { salvo de ustedes. Conmuévanse con su mundo } \\
\text { no con el mío. Cuenten sus rabias a mi déjenme } \\
\text { en paz. La paz de los libros quemados, de lo que } \\
\text { ya no es" (p. 129)." } \\
\text { Dolores: "Llegó esta comunicación, confirma lo } \\
\text { que nos dijeron en la alcaldía. Si autorizan de } \\
\text { pronto el martes podemos retirar el cuerpo de } \\
\text { Salvador" (Pág. 138) }\end{array}$ \\
\hline & & $\begin{array}{l}\text { Dolores "Es que no me han entregado su cuerpo, } \\
\text { dicen que de pronto el martes" (p. 142). }\end{array}$ \\
\hline Cuerpo-expuesto & $\begin{array}{l}\text { El cuerpo de Nirvana es el cuerpo expuesto a los } \\
\text { dispositivos y discursos de poder expresados } \\
\text { en la voz de Korvan y Agnes. Su piel y sentidos } \\
\text { son expuestos a la irrupción violenta. El cuerpo } \\
\text { expuesto ante la figura y jerarquía de poder, } \\
\text { recipiente de las violencias, el encierro al que es } \\
\text { sometido. }\end{array}$ & $\begin{array}{l}\text { En un rincón está el cuerpo de un hombre } \\
\text { amarrado, tiene un abrigo largo que le queda } \\
\text { grande y la cabeza cubierta por un saco } \\
\text { de harina" La Técnica del Hombre Blanco } \\
\text { Fragmento VI. El sótano. (Viviescas, 2000, p. } \\
\text { 335). }\end{array}$ \\
\hline Cuerpo habitado & $\begin{array}{l}\text { En el cuerpo de sujeto-creador, el autor y la } \\
\text { representación encarnan en el mismo cuerpo. } \\
\text { Desde una dimensión existencial el cuerpo es } \\
\text { habitado desde materialidad y su relación con el } \\
\text { espacio. }\end{array}$ & $\begin{array}{l}\text { "Mi culto no es el yo sino el cuerpo, en el sentido } \\
\text { sensible de la palabra cuerpo. Las cosas me } \\
\text { atañen en la medida que afectan mi cuerpo, que } \\
\text { coinciden con él, que lo conmueven y no más } \\
\text { allá". (La geografía de los nervios). }\end{array}$ \\
\hline
\end{tabular}

1 Dramaturgia y presente. Obra: Donde se descomponen las colas de los burros.

2 Fragmento de la obra, texto literario.
Tabla 1. Representación de la acción política en el cuerpo a partir de las piezas teatrales: Cuerpo ausente, cuerpo expuesto y cuerpo habitado. 
En este orden, mediante las relaciones cuerpo-ausente, cuerpo-expuesto, cuerpo-habitado, podemos encontrar como el cuerpo se construye como la superficie donde se dejan ver las formas de socialización, los poderes, las resistencias, las denuncias y el objeto propio de la creación teatral. El cuerpo aquí se halla como un significante social y productor de la memoria a través del límite, de los bordes, de la experiencia y la narración. El significado de estas figuras artístico-políticas propone vislumbrar la caracterización propuesta de la acción política expresada en el cuerpo, en tanto los productores y las propuestas se manifiestan en experiencia política. En este sentido, la autora Anne Huffschmid (2013), escribió:

En la elaboración pública de una memoria social y compartida, ésta que concierne a una sociedad en su conjunto, se cruzan distintas corporalidades y sus respectivas dimensiones afectivas: el cuerpo cargado del recuerdo de la violencia, en calidad de testigo; el otro cuerpo dolido por la ausencia que encarna la denuncia; el cuerpo del victimario y también el cuerpo receptor; el que no ha pasado por el dolor en carne propia, el visitante, el lector o la investigadora. En los procesos y lugares de memoria se trataría de conectar entre sí estas instancias en complejas dinámicas de depositar, transferir, trasladar y traducir y generar así un espacio de sensibilización social (Huffschmid, 2013).

Finalmente, vemos como en los hallazgos de la investigación, las figuras políticas de la representación corporal despliegan un conjunto de dispositivos y prácticas del poder, pero a la vez, son los elementos que trasgredir estos poderes y que dan forma y raíz a la creación teatral, mediante narrativas y significantes corporales, ante un contexto donde el cuerpo es herramienta de creación, también es territorio de denuncias, resistencias, oposiciones, resiliencias y memorias del conflicto. Se vive, se práctica, se representa y se experimenta de formas políticas en la teatralidad contemporánea.

\section{Conclusiones}

El cuerpo del artista es inseparable de la obra, es sujeto y objeto al mismo tiempo, el cual puede tener diversas prácticas, imágenes y representaciones que se ubican en una dimensión necesariamente social y política. Hallamos una corporalidad que está estrechamente ligada con la interacción social, por lo que el cuerpo es un espacio de enunciación política, una figura de implicación política o un terreno de experiencia política.

Por lo anterior, la acción política puede ser manifestada desde distintos ámbitos estéticos y artísticos, y por su ejercicio colectivo, de reconocimiento, participación o transformación colectiva, fue posible evidenciar cómo la acción política a través de la teatralidad contemporánea, busca la recuperación de lo político centrando su reflexión en formas políticas de subjetividades, denuncias, resistencias, poderes y legitimación, que sin alejarse de una mirada de lo público y lo gubernamental, profundiza en las lecturas reflexivas que puede generar el cuerpo y sus evocaciones en los procesos de creación, donde la subjetividad y lo colectivo se encuentran para otorgar un sentido político. No obstante, la definición de la acción política es de definir en sus formas teóricas y prácticas sobre los cuerpos, pues no tiene una definición estrictamente tangible, más bien es poética y construida de manera creativa desde y para los cuerpos.

Así las cosas, el cuerpo es político, porque se expresa o se experimenta de manera política, o bien es una implicación política, donde recaen discursos, poderes, resistencias, denuncias. De allí, que diversas corrientes teatrales aportaron a la significación de lo político como la búsqueda de la organicidad del cuerpo de Jerzy Grotowski, la conexión con el teatro ritual de Eugenio Barba y las técnicas corporales que posicionó Meyerhold. Cada una de ellas aportó a la reivindicación de un teatro cercano a sus públicos y a realidades sociales y políticas concretas. De igual manera, el legado de Bertold Brecht y Antonin Artaud es indiscutible, la mayoría de las piezas teatrales resultan de un 
distanciamiento con los públicos y buscan un efecto de realidad en los mismos, así como la resignificación de la materialidad del cuerpo.

Por lo anterior, podemos comprobar que los grupos de teatro se ubican en la teatralidad contemporánea, donde el cuerpo recupera todo protagonismo, y de distintas maneras resignifica la función social del arte con la vida y las experiencias personales, así como los acontecimientos que se padecen colectivamente. Allí, el teatro, la danza, la música y el performance son lenguajes artísticos que siempre van de la mano, dando lugar a un tipo de teatro difícil de clasificar para cada grupo teatral. Asimismo, el hecho de estudiar la práctica teatral contemporánea, si bien pudo generar ciertos retos para su aceptación como campo fundamental de investigación también pudo reivindicarse como dimensión importante de la sociología y las ciencias sociales, dado pues hay un vínculo relacional con los públicos, que independiente de los lenguajes, procesos y dramaturgias de cada grupo teatral, se acerca a los procesos sociales y políticos de coyuntura.

De tal manera, que la teatralidad contemporánea se articula en un sentido político desde el accionar de sus productores (actores, actrices, dramaturgos, dramaturgias y directores), como ejercicio colectivos, los cuerpos creadores proyectan el papel que se lleva construyendo desde hace casi 70 años en la creación artística contemporánea colombiana, donde la memoria es herramienta imprescindible para la construcción de narrativas nacionales, y el cuerpo se ha configurado como punto de partida y el punto de llegada de la reflexión y la práctica frente a los conflictos que envuelven el escenario colombiano.

Finalmente, esta investigación, le apuesta a la exploración de contenidos artísticos en el campo de las ciencias sociales como herramientas imprescindibles para la comprensión de los fenómenos de coyuntura, así mismo, este estudio busca contribuir a una cultura política del arte en la sociedad, como vehículo necesario para la visibilizarían de acontecimientos actuales de paz y reconciliación mediante recursos poéticos. Por lo anterior, se busca una consolidación de las memorias donde los relatos artísticos expresan y ayudan a contar lo incontable, lo relacionado con la violencia y el conflicto en Colombia en los últimos años. 


\section{Referencias}

Arendt, H. (1997) ¿Qué es la política? Barcelona: Ediciones Paidós.

Arendt, H. (1958). La condición humana. Barcelona: Ediciones Paidós.

Arboleda, A. D. (2016). "Anotaciones sobre el arte de la crítica teatral”. En La crítica: artes, medios y tendencias. Omar Rincón. Bogotá: Ediciones Uniandes.

Artaud, A. (1996). El Teatro y su doble. Barcelona: Edhasa.

Araque, C. (2013). Dramaturgia en diferencia: teatro poshistórico. Bogotá: Universidad Distrital Francisco José de Caldas.

Bachelard, G. (1993). La poética del espacio. Bogotá: Fondo de Cultura Económica.

Bourdieu, P. (1991). El sentido práctico. Madrid: Taurus.

Bourdieu, P. (2002). La distinción. Ciudad de México: Taurus.

Brecht, B. (1983). El pequeño órganon para el teatro. Granada: Don Quijote.

Castoriadis, C. (1999). Figuras de lo pensable. España: Universidad de Barcelona

De Certeau, M. (1999). “Andares de la ciudad" y “Relatos de espacio". En La invención de lo cotidiano I. Artes de Hacer. México: Universidad Iberoamericana.

Deleuze, G., y Guattari, F. (2006). Mil mesetas. Capitalismo y esquizofrenia. Valencia: pretextos.

Dewey, J. (1934). El arte como experiencia. España: Editorial Paidós. Recuperado el 29 de marzo, en http://archivos.liccom.edu.uy/ Figuras/Dewey,\%20John\%20\%20El\%20arte\%20como\%20experiencia.pdf

Dubatti, J. (2003). El convivio teatral. Teoría y práctica de Teatro Comparado. Buenos Aires: Atuel.

Duvignaud, J. (1969). Sociología del arte. Barcelona: Península.

Duvignaud, J. (1981). Sociología del teatro. Ensayo sobre las sombras colectivas. México: Fondo de Cultura Económica.

Farge, A. (2008). Efusión y tormento. El relato de los cuerpos. Historia del pueblo en el siglo XVIII. Julia Brucci (Trad.). Buenos Aires: Katz editores.

Fogari, C., y Scribano, A. (Comp.). (2009). Hacia una sociología de los cuerpos y las emociones desde América Latina. Buenos Aires: CLACSO.

Fuenmayor, V. (1999). El cuerpo de la obra. Maracaibo: Universidad del Zulia. Instituto de investigaciones Lingüísticas y Literarias.

García, S. (1998). El cuerpo en el teatro contemporáneo. Fundación el libro total. Bogotá: Sic Editorial. Recuperado el 30 de abril de 2016 de http://www.ellibrototal.com/ltotal/?t=1\&d=1320,1383,1,1,1320

Goffman, E. (1971). La presentación de la persona en la vida cotidiana. Buenos Aires: Amorrortu.

González, C. F. (1986). Historia del teatro en Colombia. Bogotá: Instituto Colombiano de Cultura.

Jaramillo, M. M. (1992). Nuevo Teatro colombiano: arte y política. Medellín: Editorial Universidad de Antioquia.

Jones, A. (2006). El cuerpo del artista. New York: Editorial Tracey Warr. Extraído en: http://historiaiuna.com.ar/wpcontent/material/2012_warr_cap-jones.pdf

Le Breton, D. (2002). La sociología del cuerpo. Buenos Aires: Nueva Visión.

Le Breton, D. (2011). Cuerpo sensible. Buenos Aires: Nueva Visión. 
Merleau-Ponty, M. (1957). Fenomenología de la percepción. México: Fondo de cultura económica.

Merleau-Ponty. M. (1945). Fenomenología de la percepción. México: Fondo de Cultura Económica.

Mouffe, Ch. (2007). En torno a lo político. México: Fondo de Cultura económica.

Nancy, J-L. (2003). Corpus. Madrid: Arena libros.

Nancy, J-L. (2007). 58 indicios sobre el cuerpo: extensión el alma. Buenos Aires: La cebra.

Nancy, J-L. (1996). Ser singular plural. Arena Libros

Rancière, J. (2005). Sobre políticas estéticas. Barcelona: Museo de Arte Contemporáneo.

Rancière, J. (2006). El viraje ético de la estética y la política. Santiago de Chile: Palinodia.

Rancière, J. (2009). El reparto de lo sensible. Estética y política. Santiago de Chile: Arcis.

Rancière, J. (2010). El espectador emancipado. Castellón: Ellago ediciones.

Sabido, O. (2007). El cuerpo y sus trazos sociales. Una perspectiva desde la sociología. Sociología y campo conceptual. México: Siglo XXI.

Sampieri, H, R. (2014). Metodología de la investigación. Ciudad de México: Interamericana editores. /Sexta edición).

Scribano, A. (2013). Encuentros creativos expresivos. Una metodología para estudiar sensibilidades. Buenos Aires: Estudios Sociológicos Editora

Sennet, R. (1997). Carne y piedra: el cuerpo y la ciudad en la civilización occidental. Madrid: Alianza Editorial.

Simmel, G. (1986). Sociología. Estudios sobre las formas de socialización. Madrid: Alianza.

Valles, M. (1999). Técnicas cualitativas de investigación: reflexión metodológica y práctica profesional. España: Editorial síntesis.

Vivas, C. (2012). Dramaturgia de lo sutil. Bogotá: Ediciones del Umbral.

Vivas, C. (2017). Dramaturgia y presente. Bogotá: Ediciones del Umbral.

Van Dijk, T. (2000). "El discurso como interacción en la sociedad”. En T. Van Dijk (Ed.), El discurso como interacción social (pp. 19-66). Barcelona: Gedisa.

Viviescas, V. (2000). Teatro. Medellín: Editorial Universidad de Antioquia.

\section{Webgrafía}

Aldana, J. (2008). Consolidación del campo teatral bogotano. Del Movimiento Nuevo Teatro al teatro contemporáneo. Recuperado el 15 de mayo de 2016 de http://www.bdigital.unal.edu.co/15100/1/962916793-1-PB.pdf

Garcés, M. El impase de lo político. Proyecto de la dimensión política contemporánea. Recuperado de http://espaienblanc.net/?ca$\mathrm{t}=10$ \& post $=582$

Grande Rosales, M. Á. (2004). Sociología del teatro: ensayo sobre las sombras colectivas. En Revista de la asociación de autores de teatro. Las puertas del drama. Siglo XXI. 19, pp. 31-33. Recuperado el 5 de mayo de https://www.academia.edu/6229021/Jean_Duvignaud._Sociolog\%C3\%A Da_del_teatro_ensayo_sobre_las_formas_colectivas?auto=download

Huffschmid, A. (2013). “La otra materialidad: cuerpos y memoria en la vía pública”. En Aguilar, Miguel, Ángel y Villagrán, Soto Paula. (2013). Cuerpos, espacios y emociones. Aproximaciones desde las ciencias sociales. Universidad Autónoma Metropolitana Unidad Iztapalapa. México D.F: Miguel Ángel Porrúa. Recuperado de http://bibliotecas.uchile.cl/documentos/20140717-0226a708034.pdf 